\title{
Perioperative and long-term outcomes of spontaneous ventilation video-assisted thoracoscopic surgery for non-small cell lung cancer
}

\author{
Jianqi Zheng $^{1 \#}$, Hengrui Liang ${ }^{1 \#}$, Runchen Wang ${ }^{1,2 \#}$, Ran Zhong ${ }^{1}$, Shunjun Jiang ${ }^{1}$, Wei Wang ${ }^{1}$, Yi Zhao ${ }^{1}$, \\ Zhuxing Chen ${ }^{1}$, Wenhua Liang ${ }^{1}$, Jun Liu ${ }^{1}$, Jianxing $\mathrm{He}^{1,2}$ \\ ${ }^{1}$ Department of Thoracic Surgery and Oncology, the First Affiliated Hospital of Guangzhou Medical University, National Center for Respiratory \\ Medicine, State Key Laboratory of Respiratory Disease, National Clinical Research Center for Respiratory Disease, Guangzhou Institute of \\ Respiratory Health, Guangzhou, China; ${ }^{2}$ Nanshan School, Guangzhou Medical University, Guangzhou, China \\ Contributions: (I) Conception and design: J Zheng, H Liang, J He; (II) Administrative support: J He, W Wang, H Liang; (III) Provision of study \\ materials or patients: H Liang, Y Zhao, J He; (IV) Collection and assembly of data: J Zheng, R Wang, S Jiang; (V) Data analysis and interpretation: J \\ Zheng, R Wang; (VI) Manuscript writing: All authors; (VII) Final approval of manuscript: All authors. \\ \#These authors contributed equally to this work. \\ Correspondence to: Jianxing He. Department of Thoracic Surgery and Oncology, the First Affiliated Hospital of Guangzhou Medical University, \\ National Center for Respiratory Medicine, State Key Laboratory of Respiratory Disease, National Clinical Research Center for Respiratory Disease, \\ Guangzhou Institute of Respiratory Health, Guangzhou, China. Email: drjianxing.he@gmail.com.
}

Background: Spontaneous ventilation video-assisted thoracoscopic surgery (SV-VATS) exhibits dual intraoperative and postoperative advantages for patients with non-small cell lung cancer (NSCLC). However, there is a lack of data regarding its long-term survival superiority over the double-lumen intubated mechanical ventilation video-assisted thoracoscopic surgery (MV-VATS) or thoracotomy.

Methods: A retrospective study was conducted from 2011 to 2018 in the First Affiliated Hospital of Guangzhou Medical University among patients with NSCLC who underwent the SV-VATS or the MVVATS. Patients receiving the SV-VATS were the study group, and patients receiving the MV-VATS were the control group. Propensity score matching (PSM) was performed to establish 1:1 SV-VATS versus MVVATS group matching to balance potential baseline confounding factors. Primary endpoints were overall survival (OS) and disease-free survival (DFS). Secondary endpoints were perioperative outcomes. The baseline information of these patients was recorded. The perioperative data and survival data were collected using a combination of electronic data record system and telephone interview. A 1:1:1 SPM was also used to compare the OS in the SV-VATS, the MV-VATS and thoracotomy group by using another database, including patients undergoing thoracotomy and the MV-VATS.

Results: For the two-group comparison, after 1:1 PSM, a matched cohort with 400 (200:200) patients was generated. The median follow-up time in this cohort was 4.78 years (IQR, 3.78-6.62 years). The OS $(\mathrm{HR}=0.567,95 \% \mathrm{CI}, 0.330$ to $0.974, \mathrm{P}=0.0498)$ and the $\mathrm{DFS}(\mathrm{HR}=0.546,95 \% \mathrm{CI}, 0.346$ to $0.863, \mathrm{P}=0.013)$ of the SV-VATS group were significantly better than the MV-VATS group. There were no statistically differences between the SV-VATS and the MV-VATS group on the operative time $(158.56 \pm 40.09 v s$. $172.06 \pm 61.75, \mathrm{P}=0.200)$ anesthesia time $(247.4 \pm 62.49$ vs. $256.7 \pm 58.52, \mathrm{P}=0.528)$, and intraoperative bleeding volume $(78.88 \pm 80.25$ vs. $109.932 \pm 180.86, \mathrm{P}=0.092)$. For the three-group comparison, after 1:1:1 PSM, 582 (194:194:194) patients were included for the comparison of SV-VATS, MV-VATS and thoracotomy. The OS of the SV-VATS group was significantly better than the thoracotomy group (HR $=0.379,95 \%$ CI, 0.233 to $0.617, \mathrm{P}<0.001)$.

Conclusions: Invasive NSCLC patients undergoing SV-VATS lobectomy demonstrated better long-term outcomes compared with MV-VATS.

$\wedge$ ORCID: 0000-0002-7545-6323. 


\begin{abstract}
Keywords: Spontaneous ventilation video-assisted thoracoscopic surgery (SV-VATS); long-term survival; nonsmall cell lung cancer (NSCLC); mechanical ventilation video-assisted thoracoscopic surgery (MV-VATS); lobectomy
\end{abstract}

Submitted Aug 09, 2021. Accepted for publication Sep 24, 2021.

doi: $10.21037 /$ tlcr-21-629

View this article at: https://dx.doi.org/10.21037/tlcr-21-629

\section{Introduction}

Since 1960 , lobectomy and systematic mediastinal lymph node dissection was the gold standard for early stage lung cancer (1). Before the widely use of video-assisted thoracoscopic surgery (VATS) in 1990s, thoracotomy was the only option in thoracic surgery $(2,3)$. The past decades have witnessed the gradual replacement of thoracotomy by double-lumen intubated mechanical ventilation videoassisted thoracoscopic surgery (MV-VATS) for its better short-term postoperative outcomes, including less incidence of complications $(4,5)$. The long-term survival outcomes of patients underwent lobectomy by MV-VATS were no inferior to thoracotomy (6). With the growing concerns on the perioperative adverse effects caused by anesthesia, such as intubation-related airway trauma, pulmonary barotrauma, muscle relaxants related postoperative myasthenia, and postoperative nausea and vomiting, non-intubated spontaneous ventilation video-assisted thoracoscopic surgery (SV-VATS) emerged (7-9).

In 2004, Pompeo et al. (10) described a series of thoracic operations under the SV-VATS, including pulmonary wedge resection and lung volume reduction. In 2011, the first lobectomy by the SV-VATS was reported by Chen et al. (11), demonstrating its feasibility and safety. At present, there are many studies on the perioperative outcomes of the SV-VATS compared to the MV-VATS, revealing that the SV-VATS exhibits a shorter postoperative hospital stay and a faster postoperative recovery $(12,13)$. Our team also demonstrated the application of the SV-VATS for lobectomy and even carinal reconstruction in our previous studies (14-17).

Though the intraoperative and postoperative advantages of SV-VATS over MV-VATS have been indicated, there is a lack of study reported its long-term benefit for patients with non-small cell lung cancer (NSCLC). Because of the relatively unstable operation field and moving of mediastinal structures, some researchers may question whether the systematic lymph node dissection under the $\mathrm{SV}$-VATS is eligible and long-term outcomes compared to MV-VATS (11). It was hypothesized that the longterm outcomes of the SV-VATS was not inferior to or even better than the MV-VATS according to the better perioperative outcomes, with less opioid use and less inflammatory response $(18,19)$.

Therefore, we attempted to explore the superiority of the SV-VATS over the MV-VATS in the long-term survival among patients with NSCLC. We present the following article in accordance with the STROBE reporting checklist (available at https://dx.doi.org/10.21037/tlcr-21-629).

\section{Methods}

\section{Study design and patients inclusion}

This is a retrospectively prognosis study. All patients with NSCLC who went through pulmonary surgery between 2011 and 2018 in the First Affiliated Hospital of Guangzhou Medical University were consecutively recruited in the retrospective database (database 1), which included 6,821 patients (6,133 MV-VATS and $688 \mathrm{SV}$-VATS). The study was conducted in accordance with the Declaration of Helsinki (as revised in 2013). The study protocol and methods were reviewed by the institutional ethics committee of the First Affiliated Hospital of Guangzhou Medical University (2020-69). Informed consent was obtained from each patient before inclusion.

Patients were included for recruitment into the database, if they met the following criteria: (I) agreed to participate; (II) underwent thoracoscopic lobectomy as well as lymphadenectomy; (III) postoperative pathology was invasive NSCLC. The following patients were excluded: (I) surgery not for lung cancer or cases with incomplete information; (II) underwent pulmonary surgery more than once; (III) underwent intraoperative radiotherapy (IORT) or thoracic hyperthermia chemotherapy; (IV) with a history of other cancer; (V) underwent thoracotomy or VATS assisted thoracotomy; (VI) underwent pneumonectomy or bilateral operation; (VII) underwent partial resection, 


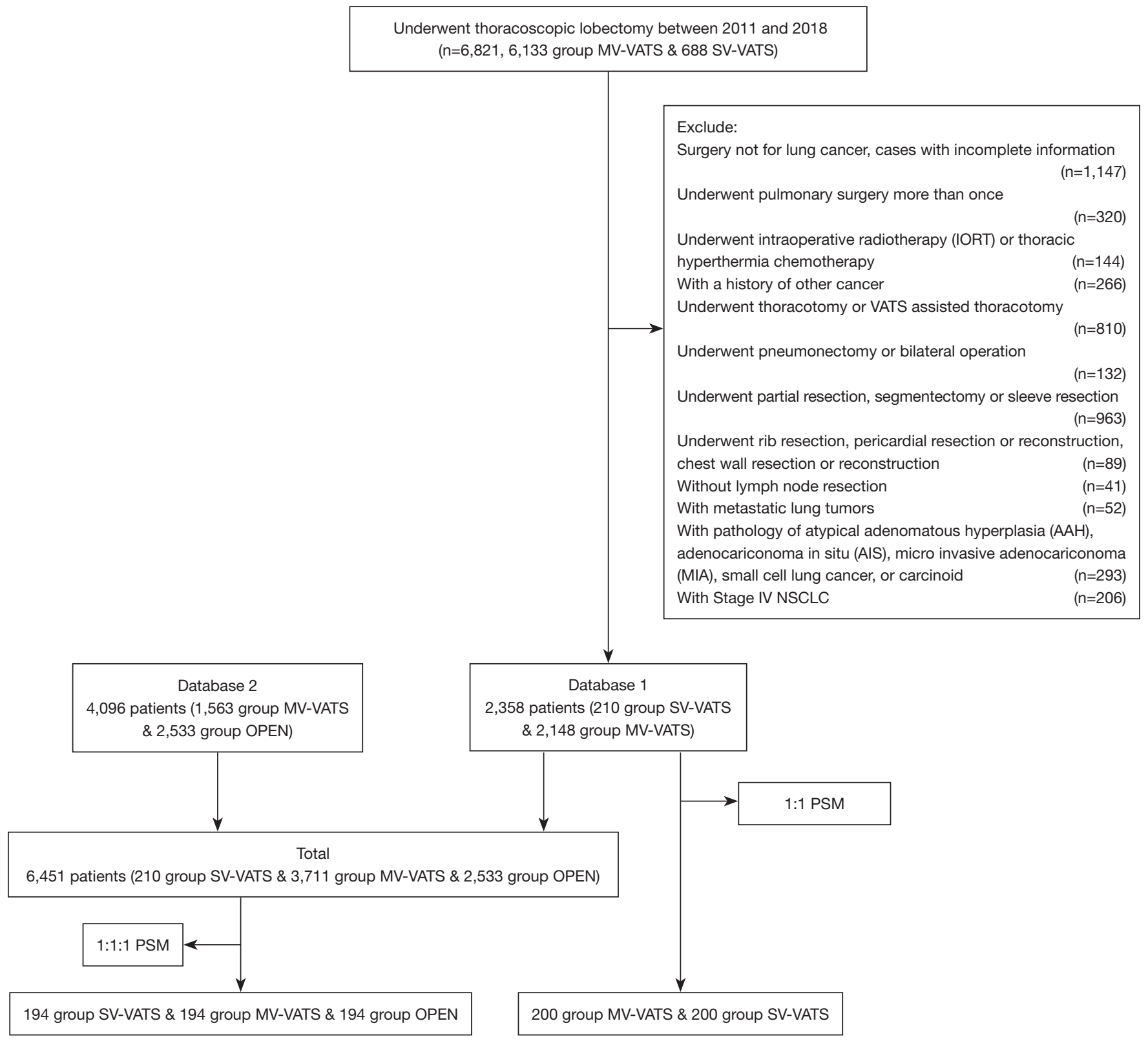

Figure 1 Flow chart of study population. MV-VATS, double-lumen intubated mechanical ventilation video-assisted thoracoscopic surgery; SV-VATS, spontaneous ventilation video-assisted thoracoscopic surgery; OPEN, thoracotomy; VATS, video-assisted thoracoscopic surgery; NSCLC, non-small cell lung cancer; PSM, propensity score matching.

segmentectomy or sleeve resection; (VIII) underwent rib resection, pericardial resection or reconstruction, chest wall resection or reconstruction; (IX) without lymph node resection; (X) with metastatic lung tumors; (XI) with the pathology of AAH (atypical adenomatous hyperplasia), AIS (adenocarcinoma in situ), etc.; (XII) with Stage IV NSCLC (Figure 1).
An informed consent for the SV-VATS or the MVVATS group was obtained from all the patients including explanation of the reason, modalities, risks and benefits. The decision of the surgical type was made by thoracic surgeons, anesthetists and patients together before operation. Patients receiving the SV-VATS were the study group, and patients receiving the MV-VATS were the control group. 
The criteria of recruiting patients under the SVVATS were as follows: ASA score (American Society of Anesthesiologists status) less than 3, without cardiovascular and pulmonary dysfunction, body mass index (BMI) less than 28 , and the diameter of tumor less than $10 \mathrm{~cm}$.

\section{Anesthesia and surgical management}

All procedures and consumption of anesthesia were described in the previous study $(18,20,21)$. Briefly, tracheal intubation ventilation was not administered throughout the operation under the SV-VATS. The double-lumen tracheal intubation was substituted as a double lumen laryngeal disposable mask airway. Also, a nasal cannula or facial mask could sometimes be a substitute for LMA (laryngeal mask airway), depending on different situations of patients. Muscle relaxant was not administered, while intravenous sedative (propofol) was sufficiently administered. Intravenous analgesics, which was mostly opioid, including remifentanil and sufentanil, was significantly reduced. Moreover, regional block anesthesia, including local anesthesia at the incision, thoracic vagus nerve block, pleural surface block, and intercostal nerve block, were applied (20). Anesthesia was conventionally administered in the MV-VATS.

Perioperatively, end-tidal carbon dioxide partial pressure, pulse oxygen saturation ( $\mathrm{SpO} 2)$, heart rate (HR), electrocardiogram (ECG), and noninvasive blood pressure were routinely measured and continuously monitored both in the SV-VATS group and the MV-VATS. To ensure that patients were at a sufficient depth of anesthesia and to avoid intraoperative awareness and excessive sedation, the Bispectral Index (BIS) was monitored and maintained at 40-60 under the SV-VATS.

The standard NSCLC radical surgery procedure, including lobectomy and lymph node dissection, was the same in both anesthesia methods. Uniportal or biportal VATS was adopted. Stryker 1288 HD 3-Chip Camera was administered in the MV-VATS and the SV-VATS. The surgical procedure and methods of lobectomy and dissection of $\mathrm{N} 1$ as well as $\mathrm{N} 2$ were the same as in the previous study in our center (22), and studies reported by Swanson et al. (4) and Shigemura et al. (23).

\section{Postoperative care and follow-up}

After surgery, patient at stage IIB to IV would receive adjuvant therapy, including chemotherapy and radiotherapy.
Patients with EGFR mutation would receive TKI. If enlarged lymph nodes were found during the follow-up period, patients would receive adjuvant radiotherapy.

Follow-up assessment for patients occurred at a 3or 6-month interval during the first 2 year after the surgery, and then once a year afterwards, which included chest computed tomography (CT) scans, brain magnetic resonance imaging (MRI) scans. Telephone follow-up was conducted every year until death or July 2021. For patients who lost to follow-up, they were evaluated by the latest medical record or telephone interview.

\section{Data collection and outcomes assessment}

The baseline information of these patients was recorded. The perioperative and survival data were collected using a combination of electronic data record system and telephone interview.

The primary outcomes included the 3- and 5-year OS rate and DFS rate of the SV-VATS and the MV-VATS group. The secondary outcomes were perioperative results, including N1 and N2 lymph node resection, days of chest tube use, operative time, anesthesia time, and intraoperative bleeding volume. The definition of N1 and N2 was according to Mountain-Dresler modification of the American Thoracic Society (MDATS) map $(24,25)$. TNM stage classification complied with the $7^{\text {th }}$ edition of TNM classification of the International Association for the Study of Lung Cancer (26).

\section{Statistical analysis}

PSM (propensity score matching) was used to control the effects of confounding factors based on the collected baseline information. A propensity score was calculated by multiple logistic regression with the following variables: age, BMI, gender, TNM stage, smoking status, and personal history, including chronic obstructive pulmonary disease (COPD), coronary disease, hypertension, cerebrovascular accident (CVA), arrhythmia, diabetes, asthma, and angina. Patients were matched at a ratio of 1:1 using a nearest-neighbor approach on the logit scale with caliper restrictions of 0.05 . PSM was performed using $\mathrm{R}$ version 4.0.4 (R Foundation for Statistical Computing, Vienna, Austria; https://www.rproject.org/). After PSM, baseline information of two groups were tested by Chi-2 test or Fisher's exact tests to examine the difference.

Continuous data were shown as mean \pm standard deviation 
(SD), and categoric data were displayed as a count and percentage of patients. Chi-square test or Fisher's exact test was applied to compare the difference of continuous data, while the Student's $t$-test was used in categorize variables. Survival analysis was performed with the Kaplan-Meier method and the log-rank test. Univariate and multivariate Cox regression analysis was conducted to assess the potential factors affecting survival. All statistical analyses were completed by IBM SPSS Statistics for Windows (Armonk, NY: IBM Corp.) and GraphPad Prism version 8.0.0 for Windows (GraphPad Software, San Diego, California USA, www.graphpad.com). $\mathrm{P}$ value $<0.05$ is considered statistically significant in all analyses. All statistical tests would be performed two-sided with a level of significance of $5 \%$.

\section{Comparison among three group (SV-VATS, MV-VATS, thoracotomy)}

In order to further explore the long-term benefit of the SV-VATS, we compared the OS of patients with NSCLC who underwent SV-VATS, MV-VATS and thoracotomy. A database (database 2) including patients undergoing thoracotomy and MV-VATS from multi-institutions in China between 2001 and 2008 was used in this study (6). Ethics approval was obtained from eight institutions. Patients with invasive lung adenocarcinoma confirmed by postoperative pathology were also recruited. PSM was used to match patients who experienced thoracotomy with those who experienced SV-VATS and MV-VATS, and the survival information was compared by Kaplan-Meier and log-rank test.

\section{Results}

\section{Patients characteristics}

For the two-group comparison, according to the inclusion and exclusion criteria, there were 2,358 patients enrolled in the study, with 210 patients undergoing the SV-VATS and 2,148 undergoing the MV-VATS (Figure 1). Four hundred (200:200) patients remained after the PSM. Features and baseline information of all patients before and after 1:1 PSM are displayed in Table 1.

\section{Perioperative outcomes}

No surgery-related death occurred. None of the patients in the SV-VATS group required conversion to the MV-VATS methods.

There were no statistically differences between two groups (SV-VATS versus MV-VATS) in the operative time $(158.56 \pm 40.09$ vs. $172.06 \pm 61.75, \mathrm{P}=0.200)$ anesthesia time (247.4 \pm 62.49 vs. $256.7 \pm 58.52, \mathrm{P}=0.528)$, and intraoperative bleeding volume $(78.88 \pm 80.25$ vs. $109.932 \pm 180.86$, $\mathrm{P}=0.092$ ).

The group numbers of $\mathrm{N} 2$ station lymph nodes $(2.63 \pm 1.11$ vs. $3.03 \pm 1.18, \mathrm{P}=0.001)$ in the SV-VATS group are less than the MV-VATS group. Lymph node number (4.64 \pm 3.9 vs. $4.78 \pm 3.49, \mathrm{P}=0.716)$, as well as the group number $(1.46 \pm 1.12$ vs. $1.47 \pm 0.99, \mathrm{P}=0.925)$ of $\mathrm{N} 1$ station and number of $\mathrm{N} 2$ station $(10.91 \pm 8.35$ vs. $12.04 \pm 7.83$, $\mathrm{P}=0.162)$, were the same between the SV-VATS and the MV-VATS group. Other preoperative, intraoperative, and postoperative outcomes were similar in two groups (Table 2).

\section{Long-term survival outcomes}

The median follow-up time in the whole cohort was 4.78 years (IQR, 3.78-6.62 years). The loss rate during follow-up was $10.25 \%$ in total. The median survival time of the SV-VATS or the MV-VATS group cannot be calculated.

In the SV-VATS group, 3-year and 5-year OS rates were $95.0 \%(91.9-98.1 \%)$ and $90.8 \%(86.1-95.5 \%)$, and 3 -year, 5-year DFS rates were $90.5 \%(86.2-94.8 \%)$ and $85.5 \%$ (79.4-91.6\%), respectively. In the MV-VATS group, 3 -year, and 5-year OS rate were $87.3 \%(82.6-92.0 \%)$ and $82.7 \%(77.2-88.2 \%)$, and 3-year, 5-year DFS rate were $80.8 \%(75.3-86.3 \%)$ and $76.3 \%$ (70.2-82.4\%) for NSCLC patients. The SV-VATS group was associated better OS (HR $=0.567,95 \%$ CI, 0.330 to $0.974, \mathrm{P}=0.0498)$ and DFS ( $\mathrm{HR}=0.546,95 \% \mathrm{CI}, 0.346$ to $0.863, \mathrm{P}=0.013)$ than the MV-VATS group (Figure 2).

Subgroup analyses according to TNM stage indicated that patients with stage III undergoing SV-VATS experienced higher OS and DFS than those undergoing MV-VATS. These results were not observed in patients with stage I and II (Figure 3).

Variables, including the mode of anesthesia methods $(\mathrm{P}=0.015)$, $\mathrm{T}$ stage $(\mathrm{P}<0.001), \mathrm{N}$ stage $(\mathrm{P}<0.001)$, and $\mathrm{TNM}$ stage $(\mathrm{P}<0.001)$ were significant prognostic factors for DFS by univariate Cox analysis, and $\mathrm{T}$ stage $(\mathrm{P}<0.001), \mathrm{N}$ stage $(\mathrm{P}<0.001)$, and $\mathrm{TNM}$ stage $(\mathrm{P}<0.001)$ were significant prognostic factors for OS. Additional multivariate analysis indicated that mode of anesthesia methods $(\mathrm{P}=0.001)$, and $\mathrm{T}$ stage $(\mathrm{P}=0.015)$ were independent factors for $\mathrm{DFS}$, 
Table 1 Baseline demographic and clinical characteristics of patients before and after 1:1 PSM

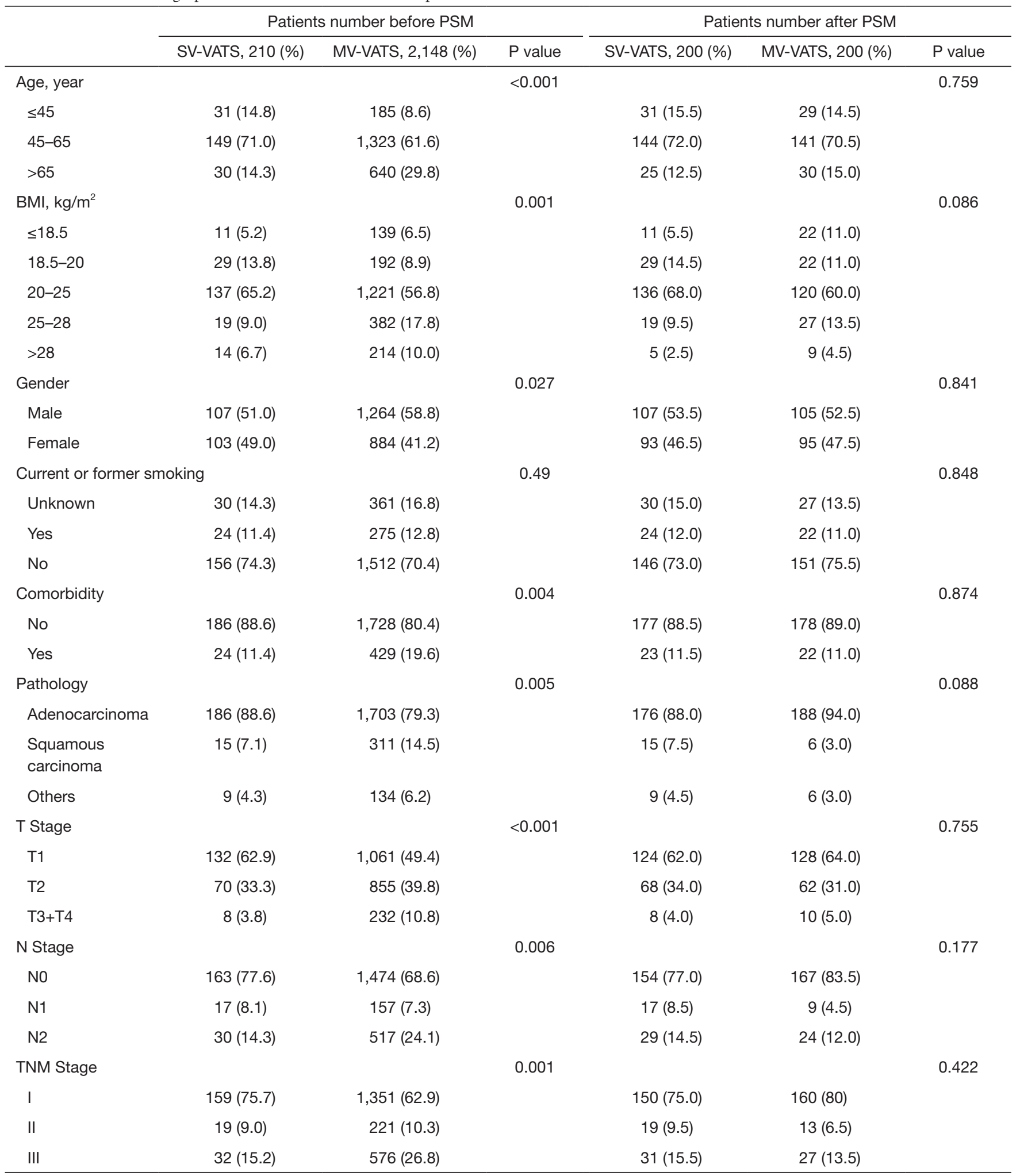

PSM, propensity score matching; SV-VATS, spontaneous ventilation video-assisted thoracoscopic surgery; MV-VATS, double-lumen intubated mechanical ventilation video-assisted thoracoscopic surgery. 
Table 2 Perioperative outcomes

\begin{tabular}{|c|c|c|c|c|c|}
\hline & \multicolumn{2}{|c|}{ MV-VATS } & \multicolumn{2}{|c|}{ SV-VATS } & $P$ value \\
\hline \multicolumn{6}{|l|}{ N1 lymph node dissection } \\
\hline Number & 4.78 & 3.49 & 4.64 & 3.9 & 0.716 \\
\hline Group number & 1.47 & 0.99 & 1.46 & 1.12 & 0.925 \\
\hline Positive group number & 0.18 & 0.58 & 0.17 & 0.48 & 0.723 \\
\hline \multicolumn{6}{|l|}{ N2 lymph node dissection } \\
\hline Number & 12.04 & 7.83 & 10.91 & 8.35 & 0.162 \\
\hline Group number & 3.03 & 1.18 & 2.63 & 1.11 & 0.001 \\
\hline Days of chest tube use, day & 4.29 & 3.02 & 4.03 & 2.19 & 0.517 \\
\hline Operative time, $\min$ & 172.06 & 61.75 & 158.56 & 40.09 & 0.200 \\
\hline Anesthesia time, min & 256.70 & 58.52 & 247.40 & 62.49 & 0.528 \\
\hline Intraoperative bleeding volume, $\mathrm{mL}$ & 109.93 & 180.86 & 78.88 & 80.25 & 0.092 \\
\hline
\end{tabular}

SV-VATS, spontaneous ventilation video-assisted thoracoscopic surgery; MV-VATS, double-lumen intubated mechanical ventilation videoassisted thoracoscopic surgery.
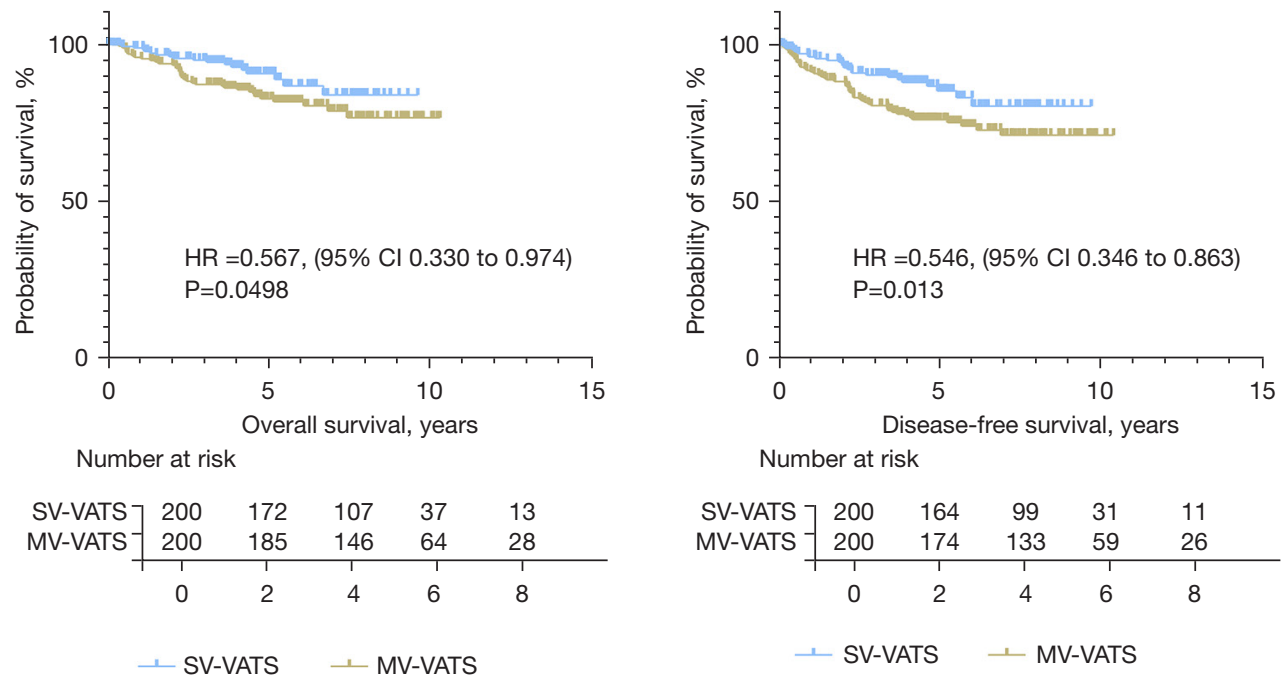

Figure 2 The long-term survival outcomes between SV-VATS and MV-VATS. MV-VATS, double-lumen intubated mechanical ventilation video-assisted thoracoscopic surgery; SV-VATS, spontaneous ventilation video-assisted thoracoscopic surgery; HR, hazard ratio; CI, confidence interval. 
A

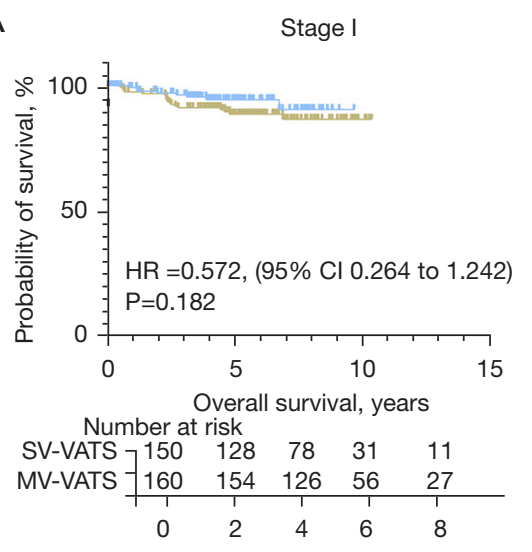

+ SV-VATS - MV-VATS
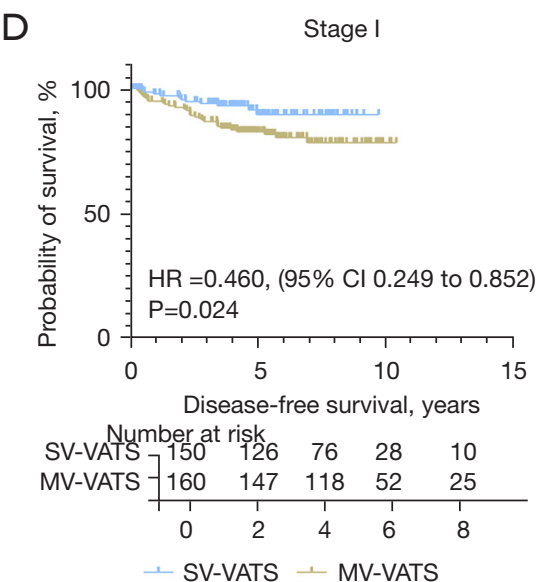

B

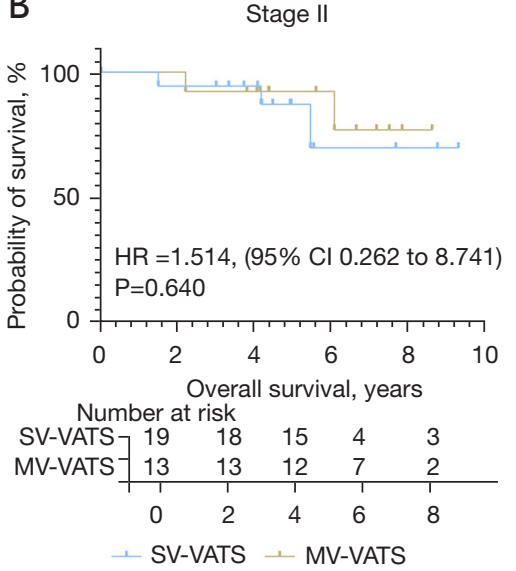

E

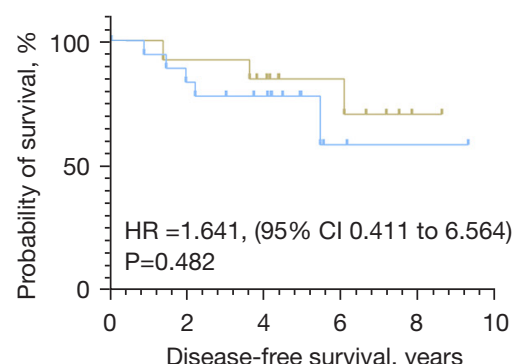

Number at risk

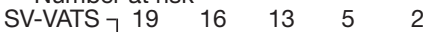

MV-VATS

\begin{tabular}{ccccc}
13 & 13 & 11 & 7 & 2 \\
\hline 0 & 2 & 4 & 6 & 8 \\
+ & SV-VATS & - & MV-VATS
\end{tabular}

C Stage III

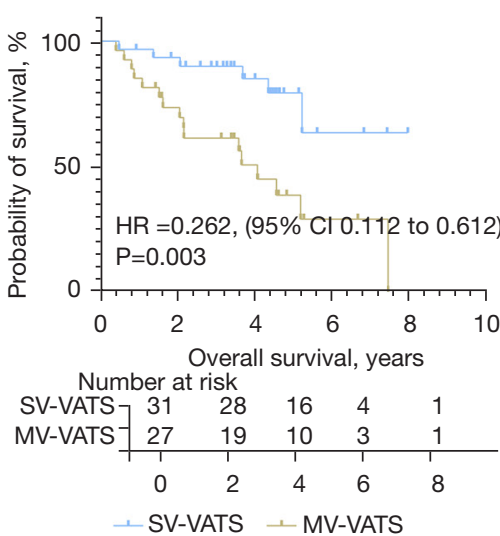

F $\quad$ Stage III

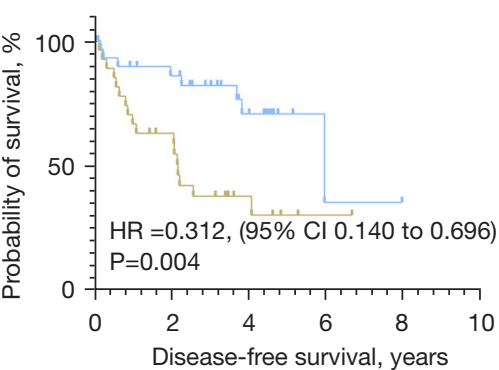

Number at risk

\begin{tabular}{|c|c|c|c|c|c|}
\hline SV-VATS $_{-}$ & 31 & 24 & 12 & 2 & 1 \\
\hline MV-VATS & 27 & 16 & 6 & 2 & 1 \\
\hline & 0 & 2 & 4 & 6 & 8 \\
\hline
\end{tabular}

Figure 3 Subgroup analyses according to TNM stage between SV-VATS and MV-VATS. MV-VATS, double-lumen intubated mechanical ventilation video-assisted thoracoscopic surgery; SV-VATS, spontaneous ventilation video-assisted thoracoscopic surgery.

and mode of anesthesia methods $(\mathrm{P}=0.004)$, and $\mathrm{T}$ stage $(\mathrm{P}=0.037)$, were independent factors for OS (Table 3).

\section{Comparison among three groups (SV-VATS, MV-VATS, thoracotomy)}

For three-group comparison, according to the inclusion and exclusion criteria, there were 6,451 patients enrolled in our study, including 2,533 patients undergoing thoracotomy in database 2, 3,711 patients undergoing the MV-VATS in both databases, and 210 patients who underwent the SV-VATS in database 1 (Figure 1). After a 1:1:1 PSM, 582 (194:194:194) patients remained. Features and baseline information of all patients before and after 1:1:1 PSM were displayed in Table 4. The median survival of the SVVATS and the MV-VATS was not reached. In SV-VATS, the 3 -year OS rate was $93.8 \%$ (95\% CI, 90.3-97.3\%) and 5-year OS rate was $89.4 \%$ (95\% CI, 84.3-94.5\%). In MVVATS, the 3 -year OS rate and 5 -year OS rate was $87.8 \%$ (95\% CI, 81.1-94.5\%) and 81.9\% (95\% CI, 75.2-88.6\%), respectively. As for thoracotomy, OS rates at 3-year was $83.5 \%$ (95\% CI, 78.1-89.0\%) and 72.5\% (95\% CI, $56.2-$ $88.8 \%)$ at 5 years. The OS of the SV-VATS group was better than the OPEN group (HR=0.379, 95\% CI, 0.233 to 0.617, $\mathrm{P}<0.001$ ), shown in Figure 4 and Table 5.

\section{Discussion}

This is a study that retrospectively proves the survival superiority of patients underwent the SV-VATS lobectomy and lymph node dissection over the MV-VATS. Our results reveal that the OS and DFS of patients undergoing the SVVATS lobectomy were significantly better than patients who undergoing the MV-VATS lobectomy and thoracotomy. 
Table 3 Univariate and multivariate cox regression analysis of prognostic factors in lung cancer

\begin{tabular}{|c|c|c|c|c|c|c|c|c|}
\hline & \multicolumn{4}{|c|}{ Univariate analysis } & \multicolumn{4}{|c|}{ Multivariate analysis } \\
\hline & $P$ value & $\mathrm{HR}(95 \% \mathrm{Cl})$ & $P$ value & $\mathrm{HR}(95 \% \mathrm{Cl})$ & $P$ value & $\mathrm{HR}(95 \% \mathrm{Cl})$ & $P$ value & $\mathrm{HR}(95 \% \mathrm{Cl})$ \\
\hline $\begin{array}{l}\text { Anesthesia } \\
\text { methods }\end{array}$ & 0.015 & 1.838 (1.128 to 2.996$)$ & 0.053 & 1.772 (0.993 to 3.161$)$ & 0.001 & 2.375 (1.421 to 3.971$)$ & 0.004 & 2.479 (1.335 to 4.606$)$ \\
\hline Gender & 0.110 & $0.683(0.428$ to 1.091$)$ & 0.157 & $0.672(0.387$ to 1.166$)$ & 0.262 & $0.759(0.469$ to 1.228$)$ & 0.195 & 0.685 (0.386 to 1.214$)$ \\
\hline $\begin{array}{l}\text { Smoking } \\
\text { history }\end{array}$ & 0.907 & $1.019(0.739$ to 1.405$)$ & 0.726 & $0.937(0.651$ to 1.349$)$ & 0.613 & $1.090(0.781$ to 1.522$)$ & 0.620 & 1.105 (0.745 to 1.638$)$ \\
\hline Pathology & 0.722 & $1.096(0.662$ to 1.813$)$ & 0.754 & $1.100(0.605$ to 1.999$)$ & 0.652 & $1.131(0.663$ to 1.929$)$ & 0.531 & 1.224 (0.650 to 2.304$)$ \\
\hline TNM stage & $<0.001$ & 1.939 (1.499 to 2.508$)$ & $<0.001$ & $2.319(1.733$ to 3.103$)$ & 0.207 & $1.752(0.734$ to 4.184$)$ & 0.087 & 2.125 (0.897 to 5.033$)$ \\
\hline
\end{tabular}

OS, overall survival; DFS, disease-free survival; $\mathrm{HR}$, hazard ratio; $\mathrm{Cl}$, confidence interval.

Previously, the characters of the non-intubated SV-VATS, included absence of endotracheal intubation and muscle relaxants during anesthesia induction, intravenous sedative, and less intravenous analgesics and opioids $(20,21)$. The SVVATS was associated with a faster postoperative recovery, decreased complications, and reduced length of hospital stay. The advantages of SV-VATS for thoracic surgery have been confirmed in our previous studies (27). Chen et al. published the first study in terms of the long-term survival result of nonintubated thoracoscopic lobectomy earlier this year. It was demonstrated that no differences were observed in recurrence rates and overall survival between nonintubated thoracoscopic lobectomy and intubated procedure (28).

One of the most essential characteristics of the SVVATS compared to the MV-VATS was the sharp reduction of opioid analgesics, which might accelerate recurrence of cancer. In vitro studies, it have been proved that opioids possess the pro-tumor activity and leads to tumor progression through immunosuppression, angiogenesis, and migration of tumor cells (29). Mu opioid receptors (MOR), one of the opioid receptors, is expressed highly in various cancers, which is associated with the direct relations with cancer or opioid immunosuppression (30-32). In a clinical study, high dose of opioid analgesics was associated with the recurrence of esophageal squamous cell carcinoma and oral cancer $(33,34)$. Nelson et al. (35) found that the consistent use of opioids for 3 to 6 months after surgery was related to worse survival outcomes of NSCLC. The regional anesthesia in SV-VATS might contribute to the reduction in the prescription of postoperative opioids, which could explain the survival advantage of the SV-VATS (20).

Another characteristic of the SV-VATS compared to the MV-VATS was full utilization of regional anesthesia $(20,21)$. A meta-analysis indicated that epidural anesthesia and analgesia might be related to the increased OS for operable oncological patients (36). Another retrospective study discovered that regional anesthesia was associated with a higher five-year survival after the bladder cancer operation (37). The regional anesthesia may influence the survival outcome of oncological patients by suppressing immune defense mechanisms in the perioperative period (38). However, there are no consensus on the association between regional anesthesia and survival outcome in oncological patients. The analysis of a randomized controlled trial (RCT) demonstrated that regional anesthesia did not associate with lower recurrence of breast cancer after surgery (39). Another RCT by Myles et al. (40), showed the negative result of the relationship between epidural analgesia and the intravenous analgesia in surgery for patients with abdominal cancers. The full utilization of regional anesthesia might contribute to the survival advantage in the SV-VATS group.

Propofol-TIVA (total intravenous anesthesia) was suggested to a higher OS in patients having cancer removal surgery (41). There were several in-vitro studies showed 
Table 4 Baseline demographic and clinical characteristics of patients before and after 1:1:1 PSM

\begin{tabular}{|c|c|c|c|c|}
\hline & \multicolumn{4}{|c|}{ Patients number after PSM } \\
\hline Age, year & & & & 0.139 \\
\hline$\leq 45$ & $27(13.7)$ & $27(13.7)$ & $30(15.2)$ & \\
\hline $45-65$ & $140(71.1)$ & $121(61.4)$ & $133(67.5)$ & \\
\hline Gender & & & & 0.841 \\
\hline Male & $102(51.8)$ & $95(48.2)$ & $102(51.8)$ & \\
\hline Female & $95(48.2)$ & $102(51.8)$ & $95(48.2)$ & \\
\hline Pathology & & & & 0.661 \\
\hline Others & $9(4.6)$ & $12(6.1)$ & $6(3.0)$ & \\
\hline T stage & & & & 0.397 \\
\hline T1 & $119(60.4)$ & $100(50.8)$ & $112(56.9)$ & \\
\hline T2 & $70(35.5)$ & $89(45.2)$ & $78(39.6)$ & \\
\hline $\mathrm{T} 3+\mathrm{T} 4$ & $8(4.1)$ & $8(4.1)$ & $7(3.6)$ & \\
\hline $\mathrm{N}$ stage & & & & 0.281 \\
\hline No & $151(76.6)$ & $156(79.2)$ & $147(74.6)$ & \\
\hline $\mathrm{N} 1$ & $16(8.1)$ & $13(6.6)$ & $25(12.7)$ & \\
\hline
\end{tabular}

SV-VATS, spontaneous ventilation video-assisted thoracoscopic surgery; MV-VATS, double-lumen intubated mechanical ventilation videoassisted thoracoscopic surgery; OPEN, thoracotomy.

a pro-metastatic impact of volatile anesthesia and an antimetastatic impact of intravenous anesthesia $(42,43)$. Iwasaki et al. (44) pointed that volatile anesthesia changed tumors environments and influenced the apoptosis of tumor cells. Zhang et al. (45) found that apoptosis of tumor cells existed, and cell proliferation was reduced when tumor cells were exposed to propofol. A meta-analysis assumed that the usage of TIVA in operation is related to improved RFS and OS in NSCLC and breast cancer compared with volatile anesthesia (41). In patients with digestive tract surgery, an observational study demonstrated a contrary result that there was no difference in OS and RFS between volatile and intravenous anesthesia (46). A retrospective cohort study showed that the relationship between different anesthesia use and long-term survival outcome of breast cancer was weak (47). In our study, TIVA was administered in the SVVATS group. We hypothesized TIVA may contribute to the positive long-term outcome in the SV-VATS compared to the MV-VATS, which warrants future studies to add clarity in contradictory findings from the current studies.

There are some limitations in our study. First, there may have been selection bias despite the use of $1: 1$ or 1:1:1 PSM, 


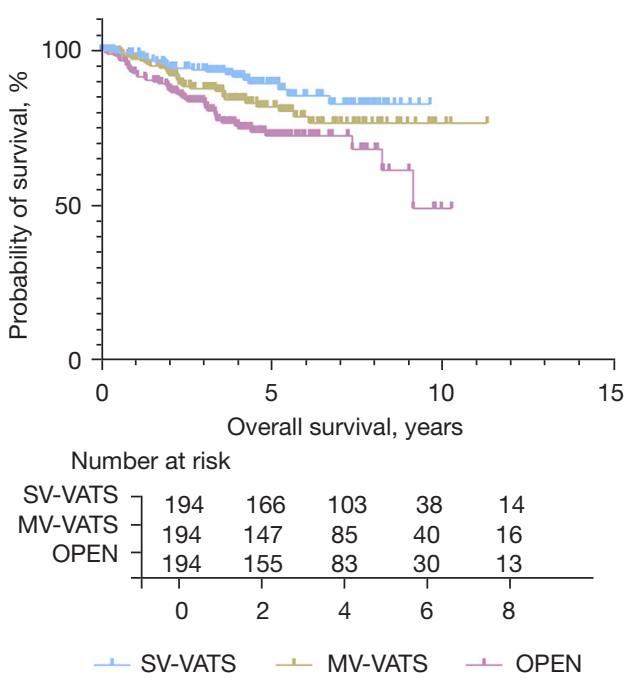

Figure 4 The long-term survival outcomes between SV-VATS, MV-VATS and OPEN group. MV-VATS, double-lumen intubated mechanical ventilation video-assisted thoracoscopic surgery; SVVATS, spontaneous ventilation video-assisted thoracoscopic surgery; OPEN, thoracotomy; HR, hazard ratio; CI, confidence interval.

Table 5 Survival information of group SV-VATS, MV-VATS and OPEN

\begin{tabular}{lccc}
\hline & HR & $95 \% \mathrm{Cl}$ & P value \\
\hline SV-VATS vs. MV-VATS & 0.606 & 0.344 to 1.068 & 0.086 \\
SV-VATS vs. OPEN & 0.379 & 0.233 to 0.617 & $<0.001$ \\
MV-VATS vs. OPEN & 0.625 & 0.397 to 0.982 & 0.045 \\
\hline
\end{tabular}

SV-VATS, spontaneous ventilation video-assisted thoracoscopic surgery; MV-VATS, double-lumen intubated mechanical ventilation video-assisted thoracoscopic surgery; OPEN, thoracotomy; OS, overall survival; $\mathrm{HR}$, hazard ratio; $\mathrm{Cl}$, confidence interval.

as patients were not randomized before the surgery and the majority of patients undergoing MV-VATS or thoracotomy were excluded after PSM in our analysis. Second, as the technique of the SV-VATS was not mature at the beginning of application, the difference in experience of surgeons may bring potential bias. Third, the sample size was not large enough. There were 400 patients included after PSM in this retrospective analysis. Besides, the follow-up time was not long enough. Though we followed up two groups of patients for more than 4 years on average, the follow-up time was not long enough to calculate the median survival time of SV-VATS. Further RCT studies and multicenter prospective observational studies need to be developed to confirm the survival advantages in the SV-VATS.

\section{Conclusions}

Invasive NSCLC patients undergoing SV-VATS lobectomy demonstrated better long-term outcomes compared with MV-VATS.

\section{Acknowledgments}

Funding: None.

\section{Footnote}

Reporting Checklist: The authors have completed the STROBE reporting checklist. Available at https://dx.doi. org/10.21037/tlcr-21-629

Data Sharing Statement: Available at https://dx.doi. org/10.21037/tlcr-21-629

Peer Review File: Available at https://dx.doi.org/10.21037/ tlcr-21-629

Conflicts of Interest: All authors have completed the ICMJE uniform disclosure form (available at https://dx.doi. org/10.21037/tlcr-21-629). All authors have completed the ICMJE uniform disclosure form. Wenhua Liang serves as the unpaid Associate Editor-in-Chief of Translational Lung Cancer Research. The other authors have no conflicts of interest to declare.

Ethical Statement: The authors are accountable for all aspects of the work in ensuring that questions related to the accuracy or integrity of any part of the work are appropriately investigated and resolved. The study was conducted in accordance with the Declaration of Helsinki (as revised in 2013). The study protocol and methods were reviewed by the institutional ethics committee of the First Affiliated Hospital of Guangzhou Medical University (2020-69). Informed consent was obtained from each patient before inclusion.

Open Access Statement: This is an Open Access article distributed in accordance with the Creative Commons Attribution-NonCommercial-NoDerivs 4.0 International 
License (CC BY-NC-ND 4.0), which permits the noncommercial replication and distribution of the article with the strict proviso that no changes or edits are made and the original work is properly cited (including links to both the formal publication through the relevant DOI and the license). See: https://creativecommons.org/licenses/by-nc-nd/4.0/.

\section{References}

1. Cahan WG. Radical lobectomy. J Thorac Cardiovasc Surg 1960;39:555-72.

2. Landreneau RJ, Mack MJ, Hazelrigg SR, et al. Videoassisted thoracic surgery: basic technical concepts and intercostal approach strategies. Ann Thorac Surg 1992;54:800-7.

3. Lewis RJ, Sisler GE, Caccavale RJ. Imaged thoracic lobectomy: should it be done? Ann Thorac Surg 1992;54:80-3.

4. Swanson SJ, Herndon JE 2nd, D'Amico TA, et al. Videoassisted thoracic surgery lobectomy: report of CALGB 39802--a prospective, multi-institution feasibility study. J Clin Oncol 2007;25:4993-7.

5. Paul S, Altorki NK, Sheng S, et al. Thoracoscopic lobectomy is associated with lower morbidity than open lobectomy: a propensity-matched analysis from the STS database. J Thorac Cardiovasc Surg 2010;139:366-78.

6. Cao C, Zhu ZH, Yan TD, et al. Video-assisted thoracic surgery versus open thoracotomy for non-small-cell lung cancer: a propensity score analysis based on a multi-institutional registry. Eur J Cardiothorac Surg 2013;44:849-54.

7. Drake-Brockman TF, Ramgolam A, Zhang G, et al. The effect of endotracheal tubes versus laryngeal mask airways on perioperative respiratory adverse events in infants: a randomised controlled trial. Lancet 2017;389:701-8.

8. Neto AS, Hemmes SN, Barbas CS, et al. Association between driving pressure and development of postoperative pulmonary complications in patients undergoing mechanical ventilation for general anaesthesia: a meta-analysis of individual patient data. Lancet Respir Med 2016;4:272-80.

9. Jiang L, Depypere L, Rocco G, et al. Spontaneous ventilation thoracoscopic thymectomy without muscle relaxant for myasthenia gravis: Comparison with "standard" thoracoscopic thymectomy. J Thorac Cardiovasc Surg 2018;155:1882-1889.e3.

10. Pompeo E, Mineo D, Rogliani P, et al. Feasibility and results of awake thoracoscopic resection of solitary pulmonary nodules. Ann Thorac Surg 2004;78:1761-8.

11. Chen JS, Cheng YJ, Hung MH, et al. Nonintubated thoracoscopic lobectomy for lung cancer. Ann Surg 2011;254:1038-43.

12. Peng G, Cui F, Ang KL, et al. Non-intubated combined with video-assisted thoracoscopic in carinal reconstruction. J Thorac Dis 2016;8:586-93.

13. Wang ML, Galvez C, Chen JS, et al. Non-intubated singleincision video-assisted thoracic surgery: a two-center cohort of 188 patients. J Thorac Dis 2017;9:2587-98.

14. Whitson BA, Andrade RS, Boettcher A, et al. Videoassisted thoracoscopic surgery is more favorable than thoracotomy for resection of clinical stage I non-small cell lung cancer. Ann Thorac Surg 2007;83:1965-70.

15. Liu J, Cui F, Pompeo E, et al. The impact of nonintubated versus intubated anaesthesia on early outcomes of video-assisted thoracoscopic anatomical resection in non-small-cell lung cancer: a propensity score matching analysis. Eur J Cardiothorac Surg 2016;50:920-5.

16. Jiang L, Liu J, Shao W, et al. Non-intubated subxiphoid uniportal video-assisted thoracoscopic thymectomy using glasses-free 3D vision. J Thorac Dis 2016;8:E1602-4.

17. Li S, Liu J, He J, et al. Video-assisted transthoracic surgery resection of a tracheal mass and reconstruction of trachea under non-intubated anesthesia with spontaneous breathing. J Thorac Dis 2016;8:575-85.

18. Liu J, Liang H, Cui F, et al. Spontaneous versus mechanical ventilation during video-assisted thoracoscopic surgery for spontaneous pneumothorax: A randomized trial. J Thorac Cardiovasc Surg 2021. [Epub ahead of print].

19. Liu J, Zeng Y, Cui F, et al. The impact of spontaneous ventilation on non-operative lung injury in thoracic surgery: a randomized controlled rabbit model study. Eur J Cardiothorac Surg 2017;52:1083-9.

20. He J, Liu J, Zhu C, et al. Expert consensus on tubeless video-assisted thoracoscopic surgery (Guangzhou). J Thorac Dis 2019;11:4101-8.

21. He J, Liu J, Zhu C, et al. Expert consensus on spontaneous ventilation video-assisted thoracoscopic surgery in primary spontaneous pneumothorax (Guangzhou). Ann Transl Med 2019;7:518.

22. He J, Yang Y, Chen M. Lobectomy by video-assisted thoracoscopic surgery. Zhonghua Wai Ke Za Zhi 1996;34:76-8.

23. Shigemura N, Hsin MK, Yim AP. Segmental rib resection for difficult cases of video-assisted thoracic surgery. J

Thorac Cardiovasc Surg 2006;132:701-2.

24. Rusch VW, Crowley J, Giroux DJ, et al. The IASLC 
Lung Cancer Staging Project: proposals for the revision of the $\mathrm{N}$ descriptors in the forthcoming seventh edition of the TNM classification for lung cancer. J Thorac Oncol 2007;2:603-12.

25. Mountain CF, Dresler CM. Regional lymph node classification for lung cancer staging. Chest 1997;111:1718-23.

26. Goldstraw P, Crowley J, Chansky K, et al. The IASLC Lung Cancer Staging Project: proposals for the revision of the TNM stage groupings in the forthcoming (seventh) edition of the TNM Classification of malignant tumours. J Thorac Oncol 2007;2:706-14.

27. Cui F, Xu K, Liang H, et al. Spontaneous ventilation versus mechanical ventilation during video-assisted thoracoscopic surgery for spontaneous pneumothorax: a study protocol for multicenter randomized controlled trial. J Thorac Dis 2020;12:1570-81.

28. Wang ML, How CH, Hung MH, et al. Longterm outcomes after nonintubated versus intubated thoracoscopic lobectomy for clinical stage I non-small cell lung cancer: A propensity-matched analysis. J Formos Med Assoc 2021. [Epub ahead of print].

29. Amaram-Davila J, Davis M, Reddy A. Opioids and Cancer Mortality. Curr Treat Options Oncol 2020;21:22.

30. Roy S, Loh HH, Barke RA. Morphine-induced suppression of thymocyte proliferation is mediated by inhibition of IL-2 synthesis. Adv Exp Med Biol 1995;373:41-8.

31. Roy S, Liu HC, Loh HH. mu-Opioid receptor-knockout mice: the role of mu-opioid receptor in gastrointestinal transit. Brain Res Mol Brain Res 1998;56:281-3.

32. Roy S, Charboneau RG, Barke RA, et al. Role of muopioid receptor in immune function. Adv Exp Med Biol 2001;493:117-26.

33. Oh TK, Jeon JH, Lee JM, et al. Association of high-dose postoperative opioids with recurrence risk in esophageal squamous cell carcinoma: reinterpreting ERAS protocols for long-term oncologic surgery outcomes. Dis Esophagus 2017;30:1-8.

34. Patino MA, Ramirez RE, Perez CA, et al. The impact of intraoperative opioid use on survival after oral cancer surgery. Oral Oncol 2017;74:1-7.

35. Nelson DB, Cata JP, Niu J, et al. Persistent opioid use is associated with worse survival after lobectomy for stage I non-small cell lung cancer. Pain 2019;160:2365-73.

36. Chen WK, Miao CH. The effect of anesthetic technique on survival in human cancers: a meta-analysis of retrospective and prospective studies. PLoS One 2013;8:e56540.
37. Jang D, Lim CS, Shin YS, et al. A comparison of regional and general anesthesia effects on 5 year survival and cancer recurrence after transurethral resection of the bladder tumor: a retrospective analysis. BMC Anesthesiol 2016;16:16.

38. Erskine R, Janicki PK, Ellis P, et al. Neutrophils from patients undergoing hip surgery exhibit enhanced movement under spinal anaesthesia compared with general anaesthesia. Can J Anaesth 1992;39:905-10.

39. Sessler DI, Pei L, Huang Y, et al. Recurrence of breast cancer after regional or general anaesthesia: a randomised controlled trial. Lancet 2019;394:1807-15.

40. Myles PS, Peyton P, Silbert B, et al. Perioperative epidural analgesia for major abdominal surgery for cancer and recurrence-free survival: randomised trial. BMJ 2011;342:d1491.

41. Yap A, Lopez-Olivo MA, Dubowitz J, et al. Anesthetic technique and cancer outcomes: a meta-analysis of total intravenous versus volatile anesthesia. Can J Anaesth 2019;66:546-61.

42. Dubowitz JA, Sloan EK, Riedel BJ. Implicating anaesthesia and the perioperative period in cancer recurrence and metastasis. Clin Exp Metastasis 2018;35:347-58.

43. Yuki $\mathrm{K}, \mathrm{Bu} \mathrm{W}, \mathrm{Xi} \mathrm{J}$, et al. Propofol shares the binding site with isoflurane and sevoflurane on leukocyte functionassociated antigen-1. Anesth Analg 2013;117:803-11.

44. Iwasaki M, Zhao H, Jaffer T, et al. Volatile anaesthetics enhance the metastasis related cellular signalling including CXCR2 of ovarian cancer cells. Oncotarget 2016;7:26042-56.

45. Zhang D, Zhou XH, Zhang J, et al. Propofol promotes cell apoptosis via inhibiting HOTAIR mediated mTOR pathway in cervical cancer. Biochem Biophys Res Commun 2015;468:561-7.

46. Makito K, Matsui H, Fushimi K, et al. Volatile versus Total Intravenous Anesthesia for Cancer Prognosis in Patients Having Digestive Cancer Surgery. Anesthesiology 2020;133:764-73.

47. Yoo S, Lee HB, Han W, et al. Total Intravenous Anesthesia versus Inhalation Anesthesia for Breast Cancer Surgery: A Retrospective Cohort Study. Anesthesiology 2019;130:31-40.

Cite this article as: Zheng $\mathrm{J}$, Liang $\mathrm{H}$, Wang $\mathrm{R}$, Zhong R, Jiang S, Wang W, Zhao Y, Chen Z, Liang W, Liu J, He J. Perioperative and long-term outcomes of spontaneous ventilation video-assisted thoracoscopic surgery for non-small cell lung cancer. Transl Lung Cancer Res 2021;10(10):38753887. doi: $10.21037 /$ tlcr-21-629 